\title{
Solvent extraction of Thorium(IV) from chloride acidic solution using Schiff base
}

\author{
Adel S. Orabi ${ }^{a}$, Mohamed F. Cheira ${ }^{b^{*}}$, Mohamed A. Hassanein ${ }^{b}$, Sami M.Y. Hassan ${ }^{a}$ \\ ${ }^{a}$ (Chemistry Department, Faculty of Science, Suez Canal University, Egypt) \\ ${ }^{b}$ (Nuclear Materials Authority, P.O. Box 530 El Maadi, Cairo, Egypt)
}

\begin{abstract}
Thorium(IV) is extracted from chloride medium by solvent extraction using a prepared Schiff base chelating agent, (E)-4-(2-hydroxy phenyl imino) pentane-2-one (AcPh) that is synthesized and characterized by FT-IR, ${ }^{1} \mathrm{H}-\mathrm{NMR}$ and elemental analysis. The obtained optimum extraction parameters were $0.02 \mathrm{M} \mathrm{AcPh} /$ chloroform and diethyl ether ratio mixture, $\mathrm{pH} 6.5,3: 1$ aqueous to organic phase ratio for $5 \mathrm{~min}$. contact time at room temperature. The thorium(IV) was then stripped into aqueous media containing $0.5 \mathrm{M} \mathrm{HNO}_{3}$ solution using of $1: 2$ aqueous to organic phase ratio for $7 \mathrm{~min}$. contact time at room temperature.
\end{abstract}

\section{Introduction}

Thorium has a huge important in the nuclear energy field. In the context of growing world population whose demand for energy is increasing, and the threat of global warming due to carbon dioxide emissions (caused by coal and hydrocarbon burning), the nuclear technology may be an attractive option especially in the developing countries (Manchanda, 2004). Thorium element is used in several of industrial and technological applications. Thorium is widely distributed in small amounts over the earth surface. It occurs in several minerals, the most common ones are monazite sand, thorianite, thorite and thoganite (Masson, et al., 2015).

Extensive efforts were recently focused on the extraction of thorium ions from its sources, some of the commonly employed separation methods; which precipitation (Armarego and Perrin, 2000), electrophoresis (Yekta, et al., 2014), electrodialysis (Mohammadi, et al., 2005), chromatography (Sharma and Sharma, 2007; Pathak and Argekar, 1992), flotation (Shiri, et al., 2011), ion exchange separation (Chen, etal., 2016; Metwally, et al., 2005) and solvent extraction (Patkar, et al., 2007) were studied. However, solvent extraction method has some advantages that are large capacity, simple equipment, quick and safe operation and low cost. Therefore it has been widely employed for the separation of precious metals from their solutions or real solution (Sole, et al., 2005).

Various extractants had been employed for the extraction of thorium, such as phosphoric acids, neutral phosphates, amines, Schiff bases, oximes, isoxazolones, crown ethers, ionic liquids, and so on $(\mathrm{Li}$, et al., 2012).

Thorium(IV) was quantitatively extracted at $\mathrm{pH} 7.5$ with $0.0001 \mathrm{M}$ of hexaacetate calix(6)arene in toluene and stripped with 0.05 M nitric acid (Malkhede, et al., 1999). Solvent extraction of thorium ion from perchlorate solution using di-dodecyl phosphoric acid, DDPA, in chloroform diluent was also carried out (Khalili, et al., 2003). A calixarene derivative, 5,11,17,23 tetra (diethoxyphospho-ryl)25,26,27,28-tetra acetoxycalix-4-arene (L) used for the separation of thorium and rare earths from nitrate medium (Yanling, et al., 2012). The extraction of thorium by $\beta$-hydroxy naphthaldoxime in presence of neutral donors and the effects of neutral organo-phosphorous compounds on the extraction of thorium by $\beta$-hydroxy naphthaldoxime in o-xylene were studied (Banerjee, et al., 2001). The extraction of thorium(IV) from nitric acid solutions by di-n-butyl sulfoxide (DBSO) in o-xylene was evaluated and the extracted species were supposed to be $\mathrm{Th}\left(\mathrm{NO}_{3}\right)_{4} \cdot 2 \mathrm{DBSO}$ wherein extraction was found to be almost independent of thorium concentration in the range between $4.3 \times 10^{-4}-4.3 \times 10^{-2} \mathrm{M}$ and inversely dependent on the temperature factor (Khan, et al., 1995).

The present study aims to the synthesized chelating agent Schiff base for the extraction and separation of Th(IV) from its acidic solutions. The effects of various experimental parameters are studied on the 
extraction of Th(IV) from a synthetic solution. These factors include $\mathrm{pH}$, extractant concentration, contact time, A/O ratio and temperature, while the stripping parameters include strippant concentration, contact time, phase ratio and reaction temperature.

\section{Experimental}

\subsection{Reagents, Solutions and Instruments}

All the chemicals and reagents used in all different parts of this work are analytical grade and used without further purification. A standard stock solution of $1000 \mathrm{mg} / \mathrm{L}$ thorium(IV) has been prepared by dissolving of $2.535 \mathrm{~g}$ thorium nitrate $\left(\mathrm{Th}\left(\mathrm{NO}_{3}\right)_{4} \cdot 6 \mathrm{H}_{2} \mathrm{O}\right)$ from Sigma-Aldrich in $1000 \mathrm{ml}$ acidified distilled water with $10 \mathrm{ml}$ concentrated hydrochloric acid. This solution is actually used to determine the relevant factors of thorium extraction upon the prepared Schiff base.

A double beam recording UV/Visible spectrophotometer model 160-A, shimadzu, Japan, is used for measuring the absorbance of the investigated solutions and for the colorimetric determination of thorium(IV). The Fourier Transform Infrared spectrometer (FT-IR) (Thermo Scientific - NICOLET iS10 USA) spectrometer has been used to characterize the major functional groups of the synthesized extractant and the thorium complex.

\subsection{Synthesis of Schiff Base}

The Schiff base ligand (E)-4-(2-hydroxy phenyl imino) pentane-2-one (AcPh) is synthesized according to Ibrahim, et al., 1998 by refluxing ethanolic solution of 10 mmole of acetyl acetone with 10 mmole of 2-aminophenol for $6 \mathrm{~h}$. Recrystallized from absolute ethanol, filtered, washed using ethanol and diethyl ether afforded pure products. The preparation of the ligand containing nitrogen and oxygen donor atoms is shown in Scheme 1.

\section{Scheme 1: (E)-4-(2-hydroxy phenyl imino) pentane-2-one (AcPh) preparation}

\subsection{Experimental procedures}

\subsubsection{Extraction investigation}

In the present work, the extraction of thorium ions from its aqueous solutions is carried out using the prepared (E)-4-(2-hydroxy phenyl imino) pentane-2-one $(\mathrm{AcPh})$, the suitable amount of the studied extractant, is dissolved in a mixture of chloroform and diethyl ether (3:2 ratio) as diluent. The aqueous phase containing thorium(IV) is adjusted to the desired $\mathrm{pH}$ value using dilute solutions of $\mathrm{HCl} / \mathrm{NaOH}$ and is equilibrated by shaking for a certain time in a glass separating funnel with an appropriate volume of the organic phase. The aqueous and organic phases are allowed to be settled, and after equilibration, they are separated completely by separatory funnel. The concentration of the Th(IV) in the aqueous phase after extraction is measured using the spectrophotometer technique by Thoron I reagent (Marczenko and Balcerzak, 2000).

The concentration of the extracted metal ions into the organic phase $\left(\mathrm{C}_{0}\right)$ is calculated based on the mass or material balance by subtracting the remainder concentration of metal ion in the aqueous phase 
after extraction $\left(\mathrm{C}_{\mathrm{A}}\right)$ from the initial concentration of metal ion before extraction $\left(\mathrm{C}_{\mathrm{i}}\right)$ (Fouad, et al., 2015). The extraction distribution coefficient $\left(D_{E}\right)$ is used as the most important index for determining the efficiency of solvent extraction process and is calculated by the following:

$$
D_{E}=\left(\frac{C_{i}-C_{A}}{C_{A}}\right) x \frac{V_{A}}{V_{O}}
$$

where the extraction distribution coefficient $\left(\mathrm{D}_{\mathrm{E}}\right)$ is defined as the concentration of species in the organic phase divided by the remained concentration in aqueous phase. The percentage of extraction $(\% \mathrm{E})$ is calculated accordingly from the equation:

$$
\% E=\frac{100 D_{E}}{D_{E}+\left(\frac{V_{A}}{V_{o}}\right)}
$$

where $\mathrm{V}_{\mathrm{A}}$ and $\mathrm{V}_{\mathrm{O}}$ are the volumes of the aqueous and organic phases, respectively.

\subsubsection{Stripping investigations}

Stripping process (back-extraction) involves bringing the thorium ions from the organic extract back into the aqueous phase. Stripping experiments are carried out by shaking different volumes of the organic phase solutions containing the extracted metal after extraction and the aqueous solution volumes of the stripping agent $\left(\mathrm{HNO}_{3}\right)$ under study for contact time ranging from 1 to $15 \mathrm{~min}$ at room temperature. After equilibration and settling, complete separation of the two phases are obtained. Known aliquot portions are carefully withdrawn from the stripping aqueous phase for measuring the concentration of the stripped thorium ions. The stripping distribution coefficient $\left(D_{S}\right)$ is used as the most important index for determining the efficiency of stripping process and is calculated by the following:

$$
D_{S}=\left(\frac{C_{A}}{C_{O}-C_{A}}\right) x \frac{V_{O}}{V_{A}}
$$

where the distribution coefficient $\left(D_{s}\right)$ is defined as the concentration of species in the aqueous phase divided by the remained concentration in organic phase after stripping process. The percentage of stripping $(\% \mathrm{~S})$ is calculated accordingly from the equation:

$$
\% S=\frac{100 D_{S}}{D_{S}+\left(\frac{V_{o}}{V_{A}}\right)}
$$

where $\mathrm{V}_{\mathrm{O}}$ and $\mathrm{V}_{\mathrm{A}}$ are the volumes of the organic and aqueous phases, respectively. All the extraction and stripping studies are carried out at ambient temperature $\left(25 \pm 1^{\circ} \mathrm{C}\right.$ ) (except when studying the effect of temperature).

The all experiments are repeated several times in order to confirm the correctness of the obtained results. The relative errors are no more than $5 \%$.

\section{Results and Discussion}

\subsection{Characterization of the Prepared Ligand}

The purity of the synthesized Schiff base is confirmed by melting point, elemental analysis, ${ }^{1} \mathrm{H}$ NMR and FT-IR analysis. 
The yield of (E)-4-(2-hydroxy phenyl imino) pentane-2-one $(\mathrm{AcPh})$ is $79.5 \%(15.9 \mathrm{~g})$ that has $184{ }^{\circ} \mathrm{C}$ melting point and yellow color (Scheme 1). The elemental analysis: calculated $\%$ for $\mathrm{C}_{11} \mathrm{H}_{13} \mathrm{NO}_{2}$ : $\mathrm{C}$; $69.08 \%, \mathrm{H} ; 6.87 \%, \mathrm{~N} ; 7.33 \%$. Found: $\mathrm{C} ; 69.13 \%, \mathrm{H} ; 6.81 \%, \mathrm{~N} ; 7.65 \%$.

The ${ }^{1} \mathrm{H}$ NMR studies of AcPh ligand (DMSO-d6) show a signal of two [- $\left.\mathrm{CH}_{3}\right]$ protons at $\delta 2.0 \mathrm{ppm}$ as singlet, the $[=\mathrm{CH}-]$ proton come to resonance at $\delta 5.19 \mathrm{ppm}$, and the 4-aromatic protons appeared at $\delta$ $6.72-7.11 \mathrm{ppm}$. The proton of $-\mathrm{OH}$ of the enol form resonate at $\delta 9.95 \mathrm{ppm}$, and the proton of $-\mathrm{OH}$ on the phenyl group come to resonance at $\delta 12.17 \mathrm{ppm}$. The protons of [ $=\mathrm{CH}-],-\mathrm{OH}$ on the phenyl group, and $\mathrm{OH}$ of the enol form are exchangeable with $\mathrm{D}_{2} \mathrm{O}$, and the HOD signal appeared at $\delta 3.7 \mathrm{ppm}$ (Salib, et al., 1991; Kwiatkowski and Kwiatkowski, 1980).

The IR spectra of the AcPh ligand gave medium and broad band centered at $3450 \mathrm{~cm}^{-1}$, which could be assigned as stretching (sym and assym) vibration of the phenolic O-H group, which is slightly disappeared in Th(IV)-complex. The change in the intensity of the $v \mathrm{O}-\mathrm{H}$ band could be denote the interaction of the phenolic $\mathrm{O}-\mathrm{H}$ with the $\mathrm{Th}(\mathrm{IV})$ ion. The bands which appeared at 1630 and $1550 \mathrm{~cm}^{-1}$ could be assigned as $v \mathrm{C}=\mathrm{O}$ and $\nu \mathrm{C}=\mathrm{N}$ bands respectively. These bands become very weaker and slightly shifted to lower wave number in the formed complex. The obtained results indicate the entrance of the $\mathrm{C}=\mathrm{O}$ and $\mathrm{C}=\mathrm{N}$ in the coordination system with metal ions. The strongly disappearance of the band $\mathrm{O}-\mathrm{H}$ group in the complex may be due to the ionization of this group in complexation.

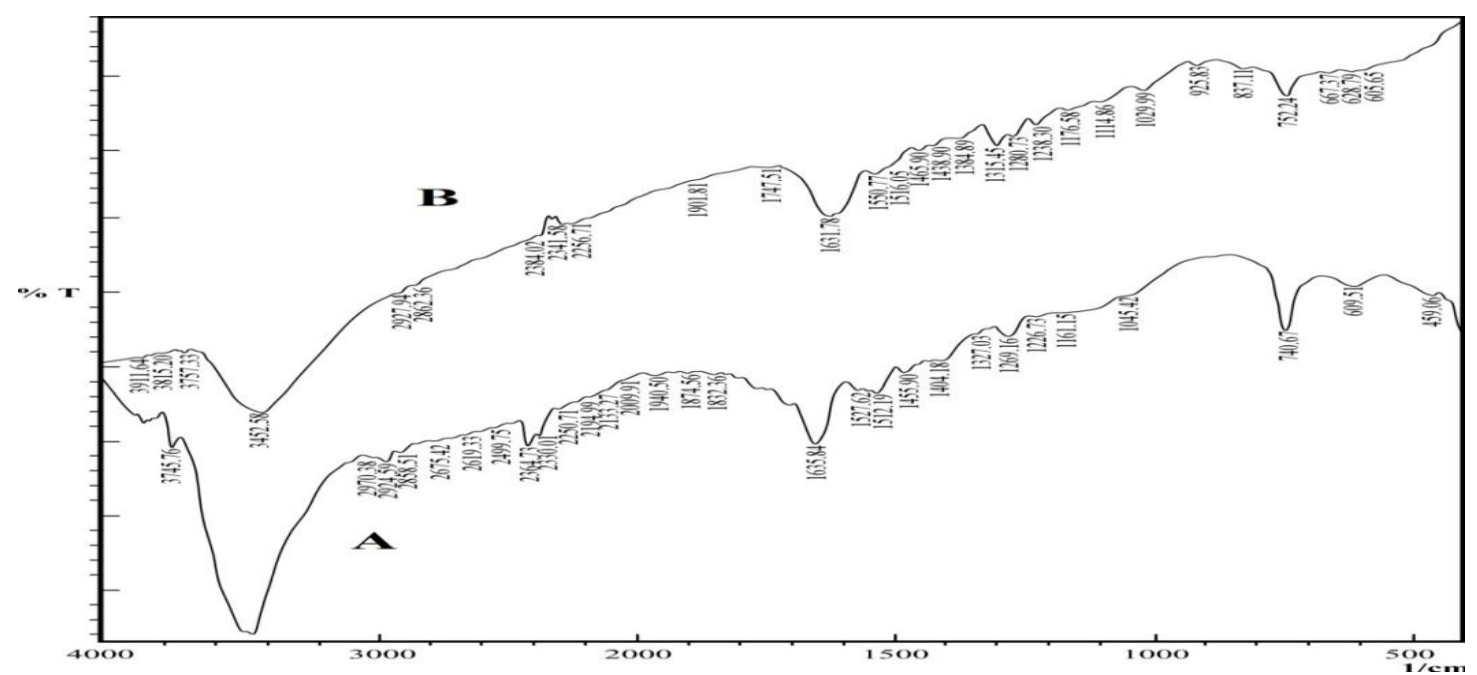

Fig. 1: FT-IR spectrum of $\mathrm{AcPh}(\mathrm{A})$ and its thorium complex (B).

\subsection{Extraction studies of thorium}

\subsubsection{Diluent type}

The dissolution of the studied Schiff base $(\mathrm{AcPh})$ is performed using various aromatic and aliphatic organic diluents, such as benzene, toluene, petroleum ether, kerosene, chlorobenzene, methylene chloride, chloroform, and diethyl ether. From the obtained results, it is found that that $\mathrm{AcPh}$ is insoluble in benzene, toluene, petroleum ether, kerosene and methylene chloride, moreover, it is partially soluble in chlorobenzene, chloroform and diethyl ether, while it is completely dissolved in chlorobenzene on heating but it returns to deposit again on cooling. To solve this problem, two diluents are synergism with each other to dissolve the $\mathrm{AcPh}$. The chloroform and diethyl ether are mixed with the ratio $3: 2$ to be completely dissolved of the AcPh.

\subsubsection{Effect of pH}

In order to study the influence of $\mathrm{pH}$ upon the extraction behaviors of thorium(IV) on the studied chelating extractant, several experiments are performed at different $\mathrm{pH}$ value ranging from 1 to 9 and other factors are fixed at $4.31 \times 10^{-4} \mathrm{M}(100 \mathrm{mg} / \mathrm{L})$ thorium ions in the aqueous solution, $0.38 \%(0.02 \mathrm{M})$ 
$\mathrm{AcPh} /$ chloroform and diethyl ether mixture and 3:1 (A/O) aqueous to organic phase ratio for $7 \mathrm{~min}$. contact time at room temperature. The $\mathrm{pH}$ of the studied thorium(IV) solutions are adjusted using $1 \mathrm{M}$ $\mathrm{HCl}$ or $1 \mathrm{M} \mathrm{NaOH}$. The concentration of the metal ions in the aqueous solution is spectrophotometrically determined after equilibrium. The results in Fig. 2, it is clearly evident that the thorium(IV) extraction efficiency on the studied extractant has gradually increased by increasing the $\mathrm{pH}$ till reaching maximum values at $\mathrm{pH} 6.5$.

At low $\mathrm{pH}$, there will be excess of $\mathrm{H}^{+}$ions in the acidic solution which could lead to the protonation of oxygen atoms of the ligand. Owing to the acidity increasing, the hydrogen ions compete for the thorium ions during the extraction process. Therefore, thorium extraction efficiency is decreased at low $\mathrm{pH}$. With increasing $\mathrm{pH}$ of the aqueous solution, the concentration of hydrogen ions in aqueous phase decreases, therefore the reaction of hydrogen ions with internal oxygen atoms of $\mathrm{AcPh}$ is decreased and the Th(IV) complex is significantly formed, leading to higher extractability of Th(IV). Hence, the selected $\mathrm{pH} 6.5$ is used for the quantitative extraction of thorium(IV) using the studied extractant which gives the highest uptake.

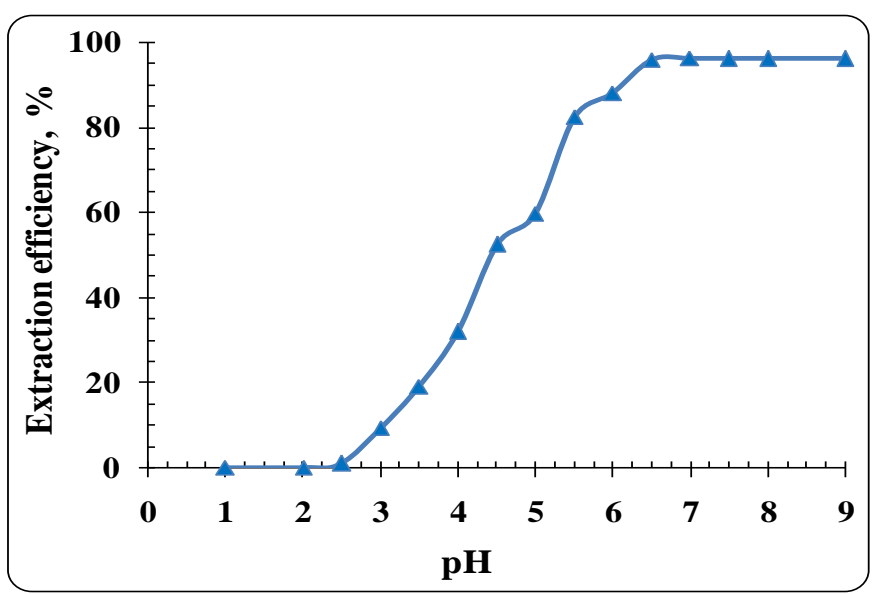

Fig. 2: Effect of pH upon the thorium extraction efficiency using AcPh extractant.

\subsubsection{Effect of extractant concentration}

The effect of $\mathrm{AcPh} / \mathrm{chloroform}+$ diethyl ether mixture concentration on the extraction efficiency of thorium ions is studied in the range from $1.0 \times 10^{-3}$ to $3 \times 10^{-2} \mathrm{M}$. In these experiments, the extraction conditions are fixed at $\mathrm{pH} 6.5$ for 7 min. shaking time and (3/1) A/O phase ratio at room temperature (Fig. 3 ). The obtained results revealed that the extraction efficiency of thorium ions is increased from 4.39 to 96.19\% with increasing the concentration of acetylacetone phenolamine ( $\mathrm{AcPh}$ ) to $0.02 \mathrm{M}(0.38 \%)$. Further increase in the extractant concentration up to $0.03 \mathrm{M}$ the extraction efficiency of thorium has not added any perceptible effect and showed a plateau due to the excess of free extractant. However, the $0.02 \mathrm{M} \mathrm{AcPh}$ is the optimum concentration for the next experiments. 


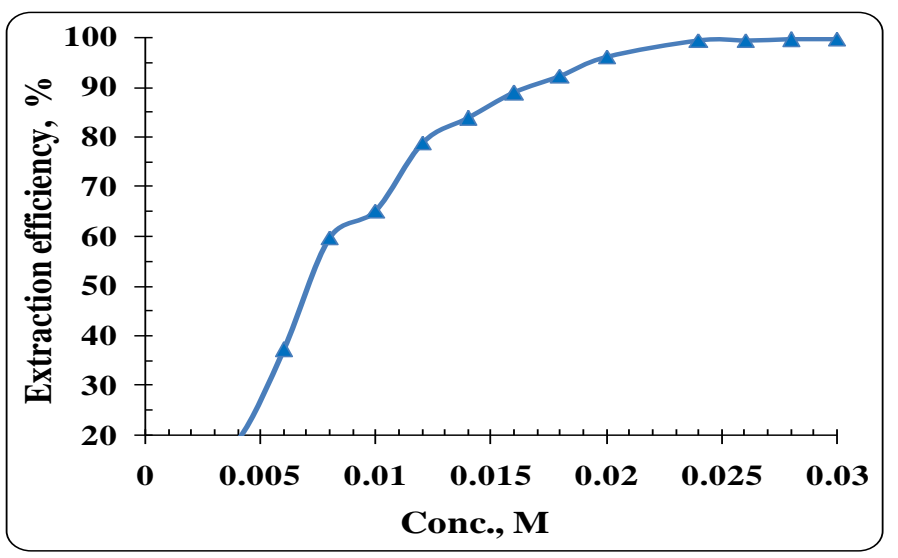

Fig. 3: Effect of AcPh Schiff base concentration upon the extraction efficiency of thorium.

\subsubsection{Effect of contact time}

A series of experiments have been applied to determine the effect of contacting time on $\mathrm{Th}(\mathrm{IV})$ extraction ranging from 1 to $10 \mathrm{~min}$ using extractant concentration of $0.02 \mathrm{M}(0.38 \%) \mathrm{AcPh} /$ chloroform and diethyl ether mixture, $\mathrm{pH} 6.5$ and 3/1 (A/O) ratio at room temperature. From the obtained data in Fig. 4 illustrate that, the Th(IV) extraction efficiency increases with contact time increases until 5 min for $\mathrm{AcPh}$ ligand and subsequently $\mathrm{Th}(\mathrm{IV})$ extraction efficiency then plateau. So a contacting time of $5 \mathrm{~min}$. is enough to attain maximum extraction efficiency attained $96.2 \%$. Therefore, the following experiments are performed by contacting the two phases for $5 \mathrm{~min}$.

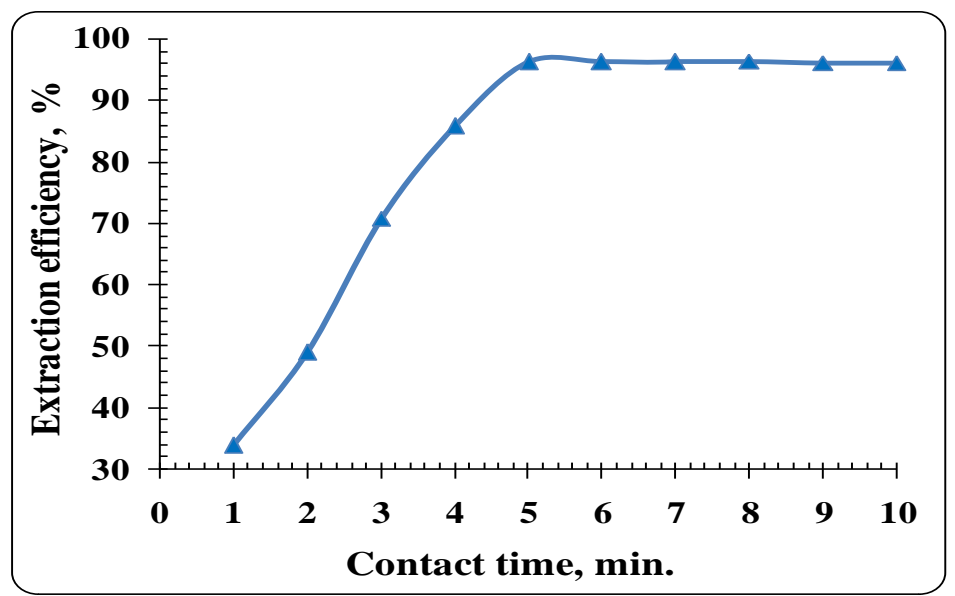

Fig. 4: Effect of contact time upon the extraction efficiency of thorium using AcPh extractant.

\subsubsection{Effect of aqueous/organic phase ratio}

Phase ratio $(\mathrm{A} / \mathrm{O})$ is one of the most important factors that affect the extraction efficiency. The effect of $\mathrm{A} / \mathrm{O}$ ratio upon $\mathrm{Th}(\mathrm{IV})$ extraction efficiency is investigated in the range $7 / 1$ to $1 / 4$ using $0.02 \mathrm{M}$ $(0.38 \%) \mathrm{AcPh} / \mathrm{chloroform}+$ diethyl ether extractant at room temperature for $5 \mathrm{~min}$. contact time, after adjusting the aqueous solution to $\mathrm{pH} 6.5$ and the thorium concentration is about $100 \mathrm{mg} / \mathrm{L}$. Mixing of the aqueous solution with the organic phase is followed by the separation of the two phases in which the thorium concentration is determined in the aqueous solution and the obtained results are plotted in Fig. 5. The latter, it is quite clear that the maximum extraction efficiency is relatively remained constant at $3 / 1$ until 1/4 A/O ratio while the maximum extraction efficiency is obtained at 3/1 A/O ratio for the AcPh Schiff base extractant. Therefore the $3 / 1$ ratio is set to be the optimum A/O phase ratio. 


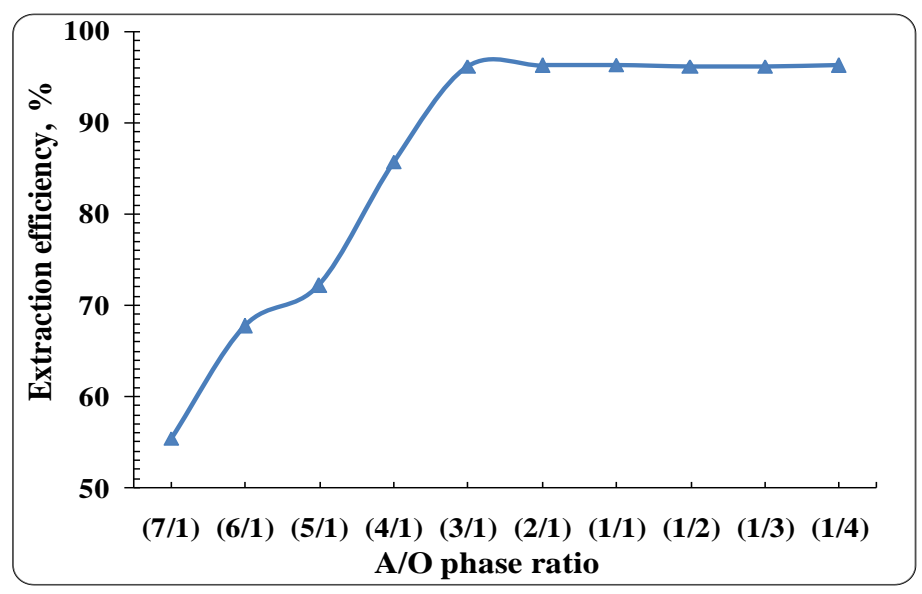

Fig. 5: Effect of A/O phase ratio upon the extraction efficiency of thorium using AcPh extractant.

\subsubsection{Effect of temperature}

The effect of temperature on Th(IV) extraction from aqueous solution is applied in the range of 25-55 ${ }^{\circ} \mathrm{C}$ using $0.02 \mathrm{M}(0.38 \%) \mathrm{AcPh} /$ chloroform + diethyl ether extractant, 3/1 aqueous/organic phase ratio, pH6.5 and $100 \mathrm{mg} / \mathrm{L}$ thorium concentration for $5 \mathrm{~min}$. contact time. From the obtained results in Fig. 7 give that the extraction efficiency of Th(IV) increase with the increase in temperature from 25 to $55{ }^{\circ} \mathrm{C}$. According to the visibility study, the room temperature is best extraction temperature. Consequently, the maximum efficiency of thorium extraction upon the synthesized extractant $\mathrm{AcPh}$ in a mixture of chloroform + diethyl ether is 96.2 which is equivalent to $288.6 \mathrm{mg}(\mathrm{Th}) / \mathrm{L}$ (organic phase). By the other words, the experimental thorium extraction capacity of AcPh extractant is $75.95 \mathrm{mg}(\mathrm{Th}) / \mathrm{g}$ (extractant). However, the extraction capacity of $\mathrm{AcPh}$ is equivalent to $75.95 \mathrm{mg}$ thorium ions per $1 \mathrm{~g}$ for $\mathrm{AcPh}$ extractant. Therefore, the extraction process is clearly favored at room temperature.

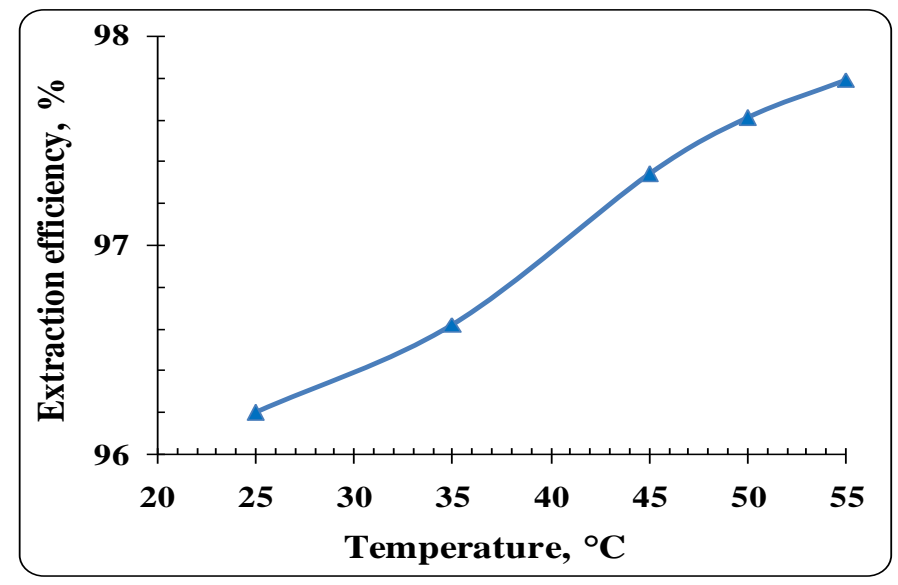

Fig. 6: Effect of temperature on the extraction efficiency of thorium using AcPh extractant.

\subsection{Stripping studies}

In the preliminary experiments aimed to strip Th(IV) from thorium loaded $0.02 \mathrm{M} \mathrm{AcPh}$ in a mixture of chloroform + diethyl ether using nitric acid solution, series of experiments are carried out to back extract thorium ions into the aqueous phase from the loaded organic phases. For this purpose, some relevant parameters are applied to find out the stripping characteristics on the extracted thorium ions such as, stripping agent concentration, contact time, A/O phase ratio, temperature and the construction of the McCabe-Thiele diagram of the stripping process. 


\subsubsection{Effect of stripping agent concentration}

To study the stripping agent concentration, Fig. 2 has actually illustrated that low Th(IV) extraction is observed at low $\mathrm{pH}$ values; a matter which implies that its stripping from the loaded $0.02 \mathrm{M}$ $\mathrm{AcPh}$ chelating ligand will occur with increasing the acid concentration. For this purpose, the different concentrations of nitric acid from 0.01 up to $1 \mathrm{M}$ are examined while the other stripping conditions are fixed at an $\mathrm{A} / \mathrm{O}$ ratio of $1 / 2$ for $7 \mathrm{~min}$. contact time at room temperature. From the obtained results given in Fig. 8, it is obvious that $0.5 \mathrm{M} \mathrm{HNO}_{3}$ has given the maximum thorium stripping efficiency of about 96.1 from the loaded $\mathrm{AcPh}$. Therefore, 0.5 M nitric acid could be adequate and recommended for next studies.

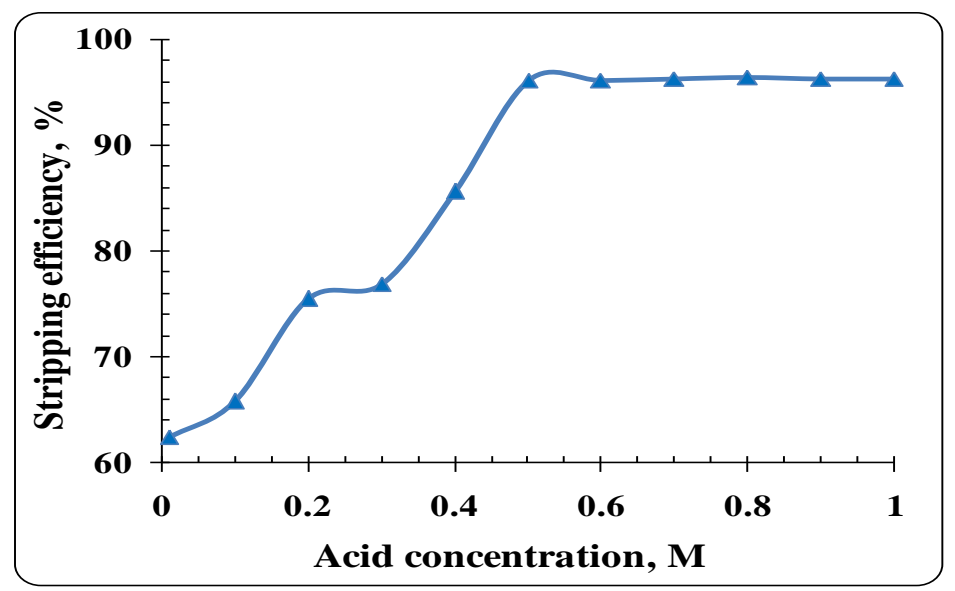

Fig. 7: Effect of nitric acid concentration on the stripping efficiency of Th(IV) from the loaded AcPh.

\subsubsection{Effect of contact time}

The effect of contact time upon thorium stripping efficiency by $0.5 \mathrm{M} \mathrm{HNO}_{3}$ from the loaded $0.02 \mathrm{M}$ $\mathrm{AcPh}$ in mixture of chloroform + diethyl ether is studied in the range from 1 to $15 \mathrm{~min}$ at the fixed conditions of A/O ratio of $1 / 2$ at room temperature. From the results shown in Fig. 9, it is indicated that the stripping efficiency of thorium increased from 72.18 to $96.01 \%$ with increasing the contact time from $1 \mathrm{~min}$ to $7 \mathrm{~min}$. After that, a contact time beyond $7 \mathrm{~min}$ did not perceptibly increase the thorium stripping from the loaded solvent beyond 96.01 for AcPh extractant. Therefore, a 7 min shaking time can be considered sufficient for quantitative stripping.

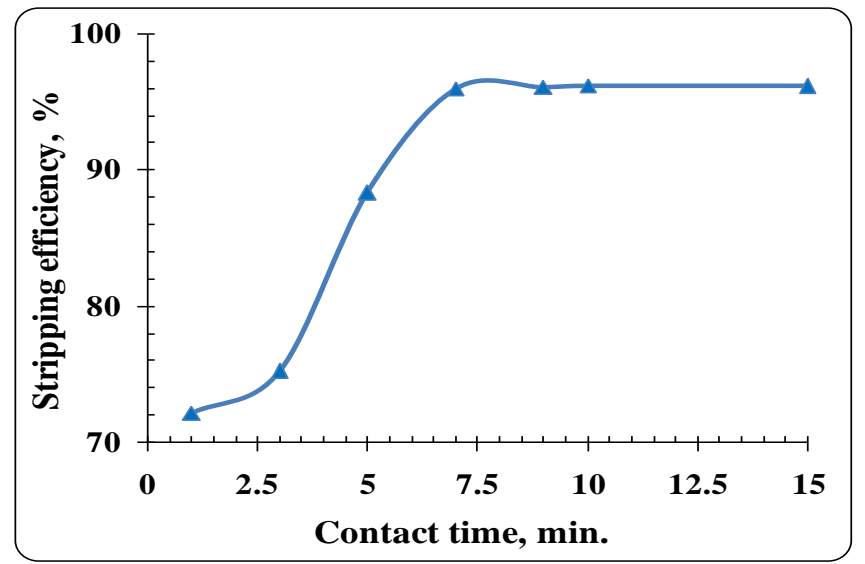

Fig. 8: Effect of contact time on the stripping efficiency of Th(IV) from the loaded AcPh. 


\subsubsection{Effect of aqueous to organic phase ratio}

In order to study the effect of the $\mathrm{A} / \mathrm{O}$ phase ratio on the thorium stripping from the loaded $0.02 \mathrm{M}$ $\mathrm{AcPh}$ in mixture of chloroform + diethyl ether $(288.6 \mathrm{mg}(\mathrm{Th}) / \mathrm{L})$, several stripping experiments are performed at $\mathrm{A} / \mathrm{O}$ ratio varying from $1 / 5$ to $3 / 1$ while the other stripping factors are fixed at $0.5 \mathrm{M} \mathrm{HNO}_{3}$ as stripping agent for $7 \mathrm{~min}$ contact time at room temperature. From the data given in Fig. 10, it is indicated that the maximum stripping efficiency from the loaded $\mathrm{AcPh}$ in its solvent is achieved at an $\mathrm{A} / \mathrm{O}$ ratio of $1: 2$ and remained constant thereafter.

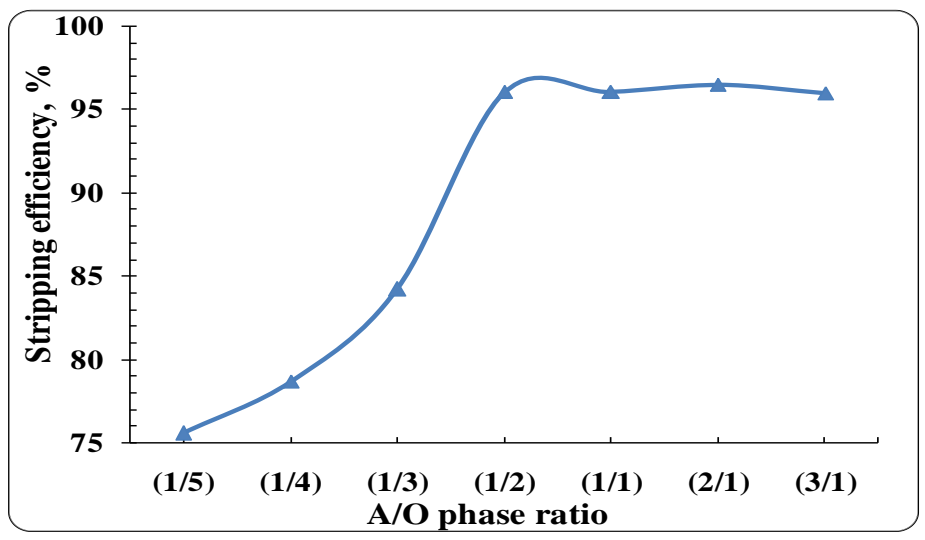

Fig. 9: Effect of A/O phase ratio on the stripping efficiency of Th(IV) from the loaded AcPh.

\subsubsection{Effect of temperature}

To investigate the effect of temperature upon the thorium stripping efficiency by $0.5 \mathrm{M}$ nitric acid from the loaded $0.02 \mathrm{M} \mathrm{AcPh}$ in mixture of chloroform + diethyl ether, several experiments have been carried out in the range from 25 up to $55^{\circ} \mathrm{C}$. In these experiments, the other stripping conditions are fixed at 7 min contact time and an A/O phase ratio of 1/2. From the obtained results given in Fig. 12, it is clear that the temperature increased from 25 to $65^{\circ} \mathrm{C}$, the stripping efficiency is progressively decreased from 96.01 down to $80.4 \%$ for $\mathrm{AcPh}$ extractant. This result could be explained by the exothermic reaction of the stripping process. Therefore, the room temperature can be considered as the best temperature for the re-extraction process.

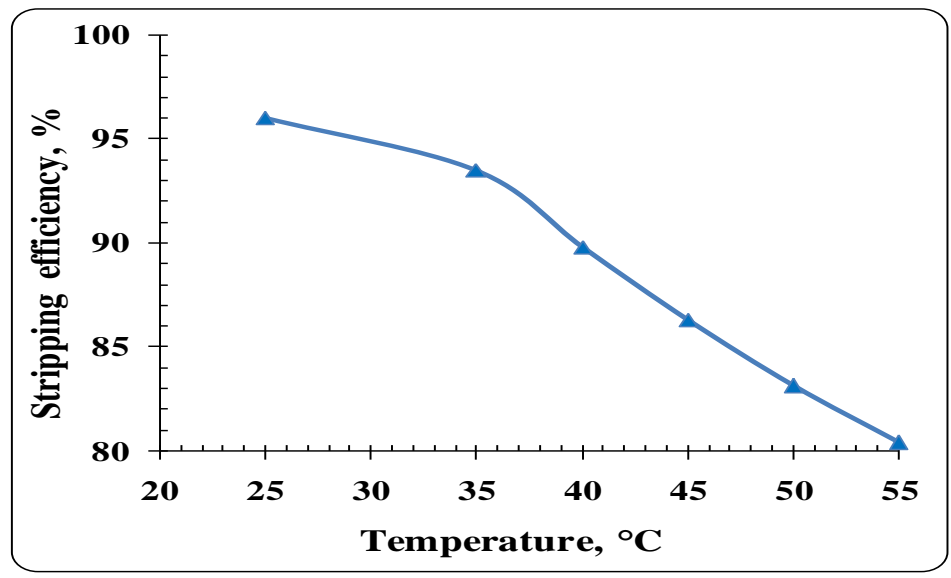

Fig. 11: Effect of temperature on the stripping efficiency of Th(IV) from the loaded AcPh.

\subsection{Regenerations of organic extractant}

For regeneration of the studied Schiff base extractant $(0.02 \mathrm{M} \mathrm{AcPh}$ in a mixture of chloroform + diethyl ether), the used organic phase is contacted with an equal volume of DI (De-ionized) water for 20 
min. The phases are separated and the $\mathrm{pH}$ of the aqueous phase is measured. The organic phase is given repeated contacts with fresh DI water until there is no change in $\mathrm{pH}$. The organic phase is then reused.

\section{Conclusion}

The extraction of Th(IV) ions using the synthesized (E)-4-(2-hydroxy phenyl imino) pentane-2-one $(\mathrm{AcPh})$ Schiff base was studied form its synthetic solution. The results showed that the maximum extraction efficiency was obtained at $0.02 \mathrm{M} \mathrm{AcPh} /$ chloroform and diethyl ether mixture, 3:1 $\mathrm{A} / \mathrm{O}$ ratio for 5 min. contact time at room temperature. The thorium(IV) is then back-extracted into aqueous media containing $0.5 \mathrm{M} \mathrm{HNO}_{3}$ using the optimum conditions $1 / 2 \mathrm{~A} / \mathrm{O}$ ratio, $7 \mathrm{~min}$. contact time at room temperature. The results of this study clearly showed the potential and versatility of (E)-4-(2-hydroxy phenyl imino) pentane-2-one for separation of Th(IV) with $96 \%$ from its acidic solution.

\section{Reference}

Armarego W.L.F., Perrin D.D, Purification of Laboratory Chemicals, Fourth edition, Reed Educational and Professional Publishing Ltd., 2000, 529p.

Banerjee S., Biswas S., Basu S., Synergistic extraction of thorium by $\beta$-hydroxy naphthald-oxime in presence of neutral donors, Journal of Radioanalytical and Nuclear Chemistry, 250(2), 2001, 399-403.

Chen Y., Wei Y., He L., Tang F., Separation of thorium and uranium in nitric acid solution using silica based anion exchange resin, Journal of Chromatography A, 1466, 2016, 37-41.

Fouad H.K., Abu-Elenein S.A., Elrakaiby R.M., Abdelmoteleb S.S., Developed spectrophotometric method for thorium determination in different Rosetta monazite concentrates using thorin dye, International Journal of Advanced Research, 3(7), 2015, 326-336.

Ibrahim S., Sallam S.A., Orabi A.S., El-Shetary B.A., Lentz A., Schiff bases of acetone derivatives: spectroscopic properties and physical constants, Monatshefte für Chemie 129, 1998, 159-171.

Khalili F.I., Mousa K.M., Soudani E.I., Solvent extraction of thorium(IV) by didodecylphoric acid, Science and Technology, 8, 2003, 107-114.

Khan M.H., Hasany S.M., Ali A., Khan M.A., Solvent extraction of thorium from nitric acid solutions using di-N-butyl sulfoxide (DBSO) in xylene, Journal of Radioanalytical and Nuclear Chemistry, 198, 1995, 409-421.

Kwiatkowski E., Kwiatkowski M., Unsymmetrical Schiff base complexes of nickel(II) and palladium(II), Inorg. Chim. Acta, 42, 1980, 197-202.

Li Y., Lu Y., Bi Y., Lo W., Extraction and separation of thorium and rare earths with 5,11,17,23tetra(diethoxy-phosphoryl)-5,26,27,28 tetraaceto-xycalix [4] arene, J. Rare Earths, 30(11), 2012, $1142-1145$.

Malkhede D.D., Dhadke P.M., Khopkar S.M., Liquid- liquid extraction of thorium (IV) with hexaacetato calix(6)arene, Journal of Radioanalytical and Nuclear Chemistry, 241(1), 1999, 179-182.

Manchanda V.K., Actinide partitioning and recovery of valuables from nuclear waste solutions, Proc. Of DAE-BRNS Theme Meeting On Emerging Trends In Separation Science \& Technology, Mumbai, 2004, p. 61.

Marczenko Z., Balcerzak M., Separation, Preconcentration and Spectrophotometry in Inorganic Analysis. Elsevier Science B.V., Amsterdam the Netherlands, 2000, 521p.

Masson O., Pourcelot L., Boulet B., Cagnat X., Videau G., Environmental releases from fuel cycle facility: part 1: radionuclide resuspension vs. stack releases on ambient airborne uranium and thorium levels, Journal of Environmental Radioactivity, 141, 2015, 146-152.

Matsushita T., Shono T., A facile synthesis of unsymmetrical tetradentate schiff-base ligands and their copper(II) and nickel(II) complexes, 5(3), 1986, 735-738.

Metwally E., Saleh A.S., El-Naggar H.A., Extraction and separation of uranium(VI) and thorium(IV) using tri-n-dodecylamine impregnated resins, Journal of Nuclear and Radiochemical Sciences, $6(2), 2005,119-126$. 
Mohammadi T., Moheb A., Sadrzadeh M., Razmi A., Modeling of metal ion removal from wastewater by electrodialysis, Separation and Purification Technology, 41(1), 2005, 73-82.

Pathak R., Argekar A., Extraction chromatographic separation of thorium(IV) with tri-n-octylphosphine oxide (TOPO), Journal of Radioanalytical and Nuclear Chemistry, 166(6), 1992, 503 -510.

Patkar S.N., Burungale A.S., Patil R.J., Separation and liquid- liquid extraction of thorium (IV) as sulfate complex with synergistic mixture of N-n-octylaniline and trioctylaniline as an extractant, Rasayan J. Chem. 2(4), 2009, 825-832.

Salib K.A.R., El-Maraghy S.B., El-Sayed S.M., Mono-, di- and tri-nuclear metal complexes of new pentadentate Schiff bases, () Indian Journal Chem., 30, 1991, 695.

Sharma M., Sharma A., Chromatography, Fifth Edition 2007, Krishna Prakashan Media (13) Ltd., 11, Shivaji Road, Meerut-250001 (UP) India, 2007, 334p.

Shiri S., Delpisheh A., Haeri A., Poornajaf A., Khezeli T., Badkiu N., Floatation-spectrophotometric Ddetermination of thorium, using complex formation with Eriochrome Cyanine R, Analytical Chemistry Insights, 6, 2011, 1-6.

Sole K.S., Feather A.M., Cole P.M., Solvent extraction in southern Africa: an update of some recent hydrometallurgical developments, Hydrometallurgy, 78(1), 2005, 52-78.

Yanling L., Youcai L., Yan B., Wuping L., Extraction and separation of thorium and rare earths with 5,11,17,23- tetra(diethoxyphosphoryl)-25,26,27,28-tetra-acetoxycalix[4]arene, Journal of Rare Earths, 30(11), 2012, 1142-1145.

Yekta Z.S., Nilchi A., Yaftian M.R., Yousefnia H., Separation and direct UV detection of complexed lanthanides, thorium and uranyl ions with 2-thenoyltrifluoroacetone by using capillary zone electrophoresis, Journal of Radioanalytical and Nuclear Chemistry, 302(3), 2014, 1143-1150. 


\title{
إستخلاص أيونات الثوريوم بإستخدام قاعدة شيف من المحلول الحامضي
}

\author{
عادل سيد عر ابي ${ }^{1}$ ، محمد فريد شعيرة 2، محمد عبدالمقصود حسنين2 ، سامي مظهر يوسف حسن 1 \\ 1 ـ ـ قسم الكيمياء ـ كلية العلوم - جامعة قناة السويس - مصر

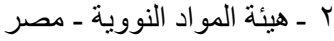

الهدف من البحث إستخلاص أيونات الثوريوم من وسط حامضي بإستخدام تقنية الإستخلاص بالمذيب العضوي بقاعدة شيف المحضرة من تفاعل 10 مللي مول من 2- أمينو فينول مع 10 ملإي بلي مول أسيتيل أسيتون وتم توصيف الناتج (AcPh) بإستخدام ألتحليل العنصري و تحليل الأشعة تحت

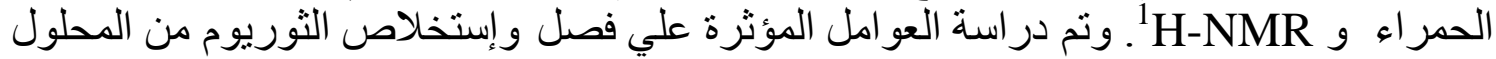

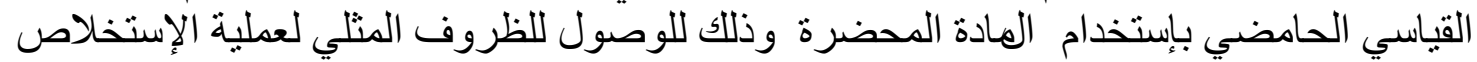
و هي تم إذابة قاعدة شيف المحضرة في مخلوط من الكلوروفورة و و ثنائي إيثيل إيثير إذابة كاملة بنسبة 23:2، قيمة الأس الهيدروجيني هي

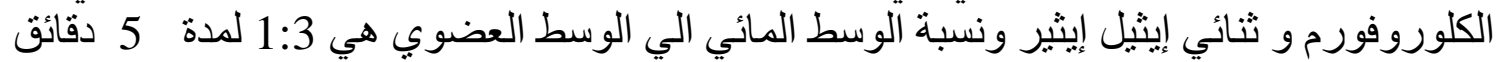

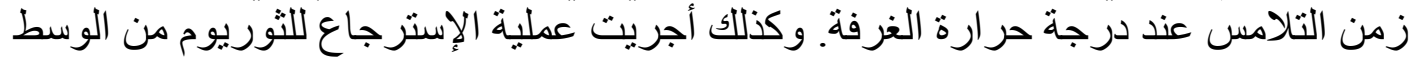
العضوي المحمل بالثوريوم للوصول للظروف المثلي وهي الوسط المائي الي الوسط العضوي هي

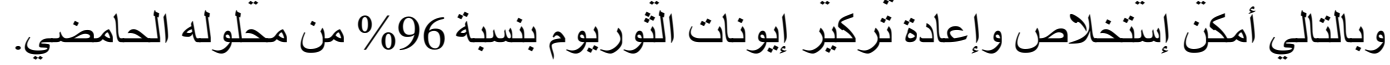

